\title{
File Hygiene and BIM Models Restrictions
}

\author{
Andrzej Szymon Borkowski* \\ Department of Spatial Planning and Environmental Sciences, Warsaw University of Technology, Poland \\ *Corresponding author: Andrzej Szymon Borkowski, Department of Spatial Planning and Environmental Sciences, Faculty of \\ Geodesy and Cartography, Warsaw University of Technology, Warsaw, Poland
}

\begin{abstract}
The efficiency of the BIM model depends not only on the knowledge and skills of the designer, but also on the applied software. Applications in the BIM technology allow users for the optimization of the model through a number of activities performed during the design process. The article presents models of conduct both developed by designers and recommended by software producers. The application of the specified good practices in work with a project ensures a stable and effective course of the design process. The presented guidelines are described as a set of tools that can be used individually or in combination, for the purpose of development of coherent BIM models possible to calculate, and coherent with the design concept.
\end{abstract}

Keywords: Building information modeling; File hygiene; Restrictions of models; Optimization

\section{Introduction}

The building information modeling (BIM) is a new tool used by the architecture, engineering and construction industry to design and build new buildings. Similar to manufacturing companies, architects and engineers are using digital prototypes in building design [1].The currently designed BIM models are based on semantic data structures, object-oriented software, and parametricity. The terms frequently occur in descriptions of standards of the building SMART organization (http://www.buildingsmart.org) [2] and in folders of BIM software producers. Semantic data structures are based on objects and relations between them. Semantic data structures are usually composed of data originating from different sources (bases), and permit storing of not only numerical or textual data, but also relations between them and their restrictions. Objectoriented software in BIM permits a transition from the general to the particular, e.g. building first, then storey, followed by room, equipment of rooms, etc. Objects kept in data bases are described in a complicated way, but providing for unambiguous character of the message. Ontology of data bases categories, hierarchies, and defines terms. The parametricity of 3D models involves a twoway association of features of the modeled object (dimensional, geometric, physical) with the model itself by means of so-called bonds. The parametricity of the BIM model is a feature making the work of a designer considerably easier [3].

Constructed BIM models should be useful and meet the expectations of stakeholders, and provide for interoperability [4].
In order for the BIM model to be 'good' and meet the expectations of users, files of the model must be 'hygienic', i.e. during work with the model, certain rules and good practices should be observed. BIM file hygiene ensures access to information that is valid, complete, legible, available, protected, and easy to modify [5]. File hygiene concerns aspects of work of a designer such as e.g. the absolute/ relative location (path) of dependent files, work with families/ groups/sets of elements, display and modification of views, or adding and using tasks in a project. The application of good practices developed by other designers and software producers will allow the designer to avoid different undesired problems, and will make the model 'good'.

However, even models with a high degree of detail - LoD 5 or 6 [6], have certain restrictions that can make the designing process and collaboration in the BIM technology difficult, reducing the efficiency of the model. The problems can concern among others sharing work, preparing variants of the project, or importing and combining other files. Technical comments concerning the efficiency of models, provided in this article, can be referred to models developed in the most popular BIM applications such as Revit, ArchiCAD, Vectorworks, etc. The awareness of limitations of constructed models and current file hygiene allow the designer to develop a BIM model devoid of errors and corresponding with the concept of lean processes, agile management, and sustainable construction [7]. Building construction is following the path through BIM and 'digital construction' [8]. 


\section{File Hygiene}

During work with files of a BIM model, their 'hygiene' should be kept, i.e. relevant responses to the occurring problems/situations/ notifications should be implemented. Two types of notifications usually occur in BIM applications: warnings and errors. A warning notification can be usually omitted and ignored. This, however, usually leads to a situation in which the problem is not solved, and the warning keeps being recorded in the file structure. Therefore, it takes physical memory and increases the size of the file. Warnings should always be scrupulously read and solved. In the case of an error notification, the programme will not permit moving on to the next step without solving the problem (in this situation the designer is forced to solve the problem). The next aspect concerns the location (paths) of combined files. The designer should not use mapped discs, but always save files of the model directly on the hard disc of the computer or in the cloud. In the case of shared files (processed by several persons in the scope of teamwork), the central model should be saved in a safe place (preferably in the cloud or internal network) with exclusive access of entitled persons. Each of the designers participating in the shared project should work on a local copy of the central model, synchronizing their work results to the central model (Figure 1). The designer should also limit the number of files (.dwg, .pdf etc.) attached to the model to the necessary minimum, and delete files from the model on the current basis if they become redundant.

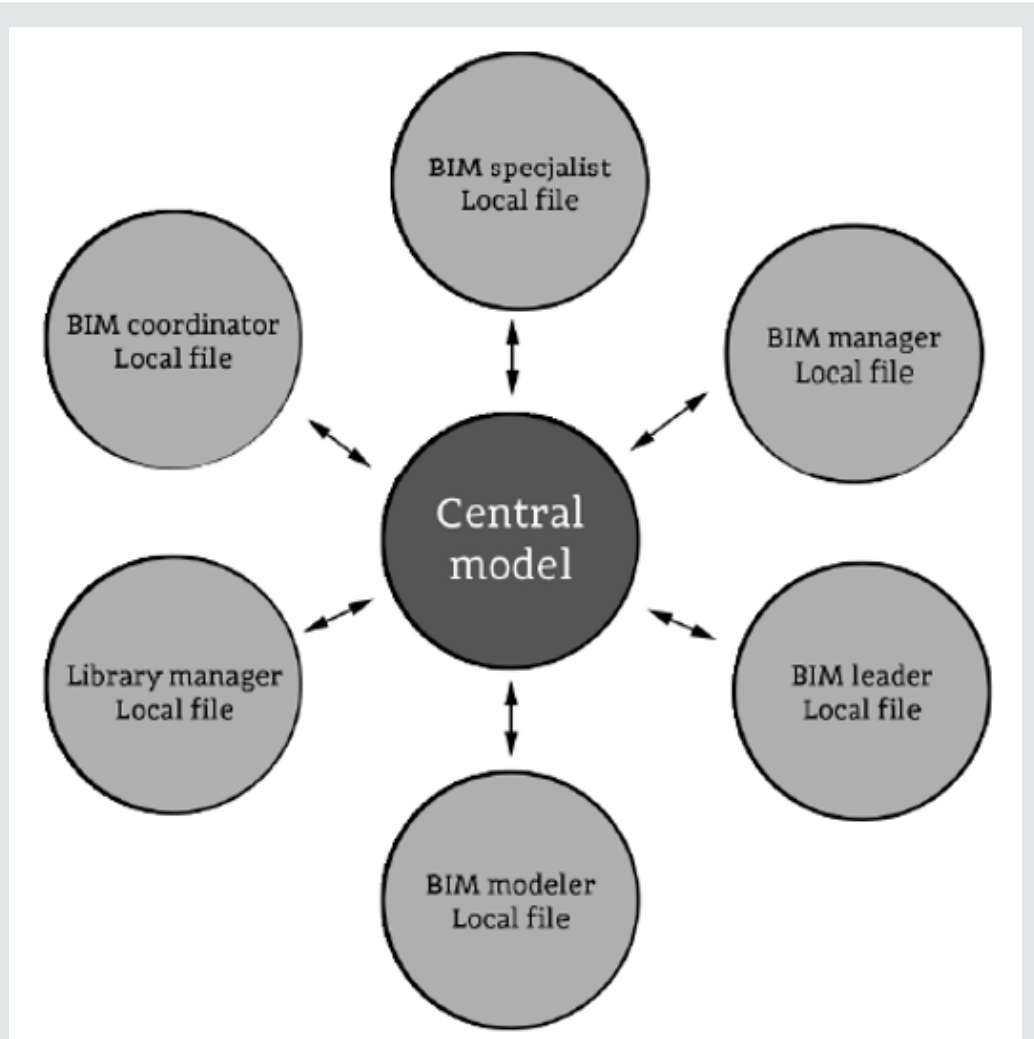

Figure 1: Synchronization of local files with the central model.

BIM models are particularly composed of Components. A Component is the basic component of information on the object. A Type describes the group of components of the same type. A System permits grouping different components by requirements specified by the owner. In addition to the aforementioned, the designer uses Spaces, Zones, Storeys, Objects, or Shared Resources in the project [9]. In the case of using components, it is advisable that the designer uses ready solutions, i.e. ready 3D models of particular producers (if they are properly prepared), but if they have to model a component themselves, they should model them as system or loadable components, so that they can be used in other files or projects. The development of so-called local components makes their use for the purposes of other projects impossible. In the case of modeling components, it is worth paying attention to openings in forms- they are very memory-consuming, and their occurrence should be minimized.
The designer uses different views during work (projections, elevations, 3D views). A BIM model can include several tens, or even several hundred of them. The designer should minimize their number, delete sample cameras or renders, and should not multiply views for the performance of simple activities (in such cases, the existing view or working plane can be often used). In work with 3D views, it is better to work in a border or shaded style of view. They are three times more efficient than the hidden line or realistic style. Too many elements in views should be avoided. It is better to control them from the level of management of the graphics of a given view, or develop separate templates of views for particular industries (e.g. HVAC). 'Smart' work with views is very important. The depth of views in elevation, projection, or cross-section should be possibly minimized, so that geometry hidden by other elements in the view has no effect on the efficiency of the model (Figure 2). 

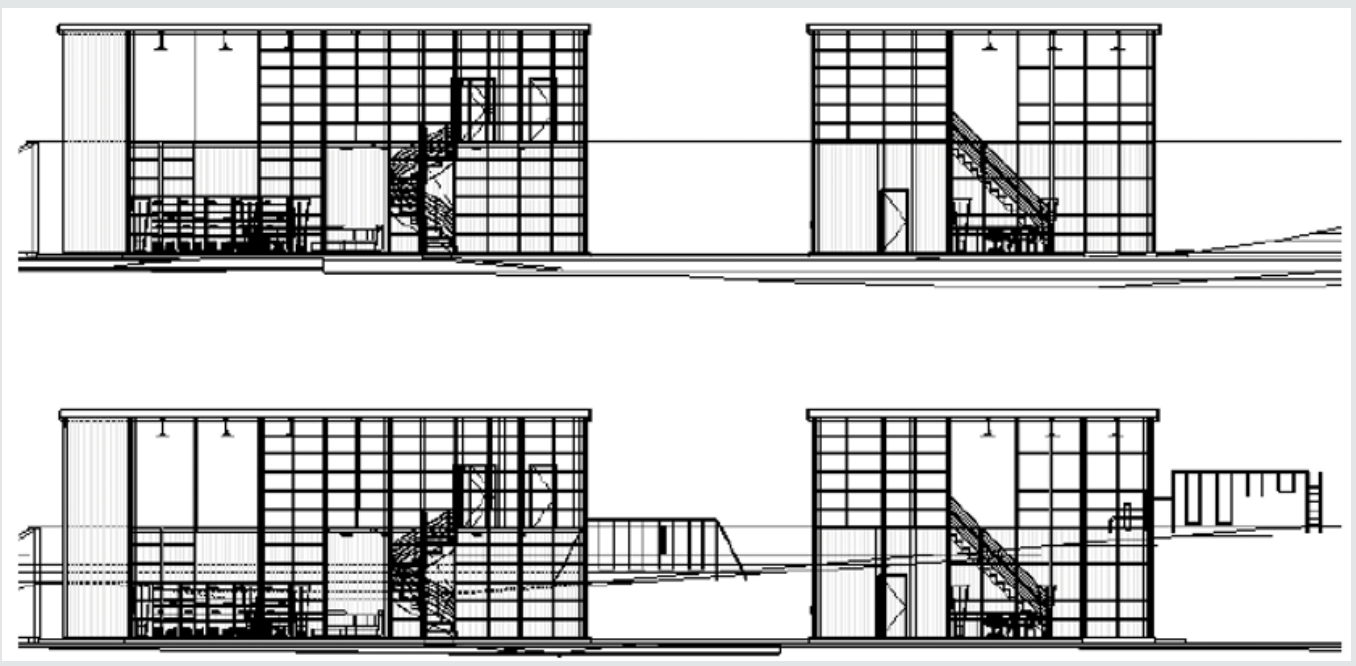

Figure 2: The east elevation of unlimited and limited depth of view.

In the case of large models, their scope in 3D views should be limited. It is also better to avoid hiding too many elements in a given view not to overload the model. It is worth closing unnecessary windows with views, particularly during saving the central file, because during updates, complex views constitute an element of the update. In views themselves, you can determine the level of detail, view sunshine, shade, or other important elements. If they are not absolutely necessary, they should be turned off. Graphics view style settings in particular views have more effect on the efficiency of manipulations (i.e. zooming in, zooming out, dragging, rotating). Due to this, it is worth distinguishing modeling views (for designing) and sheet views (for printing) by means of names and areas. This way they can be logically ordered, and their appropriate use can be facilitated. Excessive modeling of 3D joints such as metal sheets or screws should be avoided. During processing of typical details, 2D details of joints of components should be created, or the existing ones should be used.

The last important issue is industry cooperation. Building tasks during sharing of files is usually optional. It is worth doing so, however, for clarity of division of obligations, and for order in the scope of ownership of components. Building tasks (even in the case of individual work) makes work less strenuous and allows for avoiding chaos. Turning off tasks in a project causes physical turning off of a part of a model. The procedure is not only applied in work across industries and in teamwork, but also in work in very large files. Tasks ascribed to particular designers also offer other advantages:

(i) They can be loaned,

(ii) They can be open for everyone, hidden, or non-editable,

(iii) They can constitute new variants or design solutions. It is recommended to apply tasks for the purpose of separation of conceptual areas of the design, such as:

1. Separate buildings,

2. Grids and levels,
3. Structural layer of the building,

4. Building envelope,

5. Furniture and equipment belonging to many categories,

6. Spatially identified areas of a single building (for example wings),

7. Attached RVT and DWG files,

8. Rooms and spaces.

Creating a task can prove useful if some elements of the model such as the building grid or attached files must be protected from incidental change. Then, BIM managers or team managers can sometimes decide to create tasks containing such elements so that they are not incidentally moved or edited. Industry cooperation in BIM does not only strengthen and accelerate design works, but also facilitates communication on many levels of collaboration in the supply chain at the stage of implementation of the design [10]. There are also bottom-up methods of work planning. Work packaging is currently challenging and time consuming. BIM is used to automate work packaging where interdependent activities are assigned to the same work package [11].

\section{BIM Model Restrictions}

The involvement of the construction industry in BIM is particularly used as a common platform of exchange of information between many specialists, suppliers, and constructors. It usually covers a shared model for the proposed design with data from different team members. This strengthens and accelerates the dialogue between different team members [12]. Like any model, the BIM model is not perfect, and can have certain restrictions. The restrictions may occur both on the side of the used equipment and construction of the model itself, or its use. This article particularly focuses on the efficiency of the model itself during its development and further use. The efficiency of a BIM model can be generally affected by the following features: complex geometry, many parametric dependencies, many bonds, complex views, or attached files. In certain situations in the designing process the application of 
specified procedures is recommended. Verifying the model and its particular components helps optimize the efficiency of the model.

The most significant restriction of the BIM model can be the lack or limited interoperability. However, the majority of software available in the marker already ensures interoperability of its applications, e.g. through the IFC format. Interoperability of the BIM model is particularly important at the designing stage, when work on the project is performed by designers of different industries using different applications. Interoperability can be ensured due to association through an interface (uni- or bidirectional) of e.g. applications from the Autodesk group (Figure 3) or by means of a shared data exchange file. The use of the same shared data file by different applications seems to be an ideal solution. For interoperability can be developed a specification based on the performance of the model. Interoperability specification provides a coherent view of integrated BIM use [13].

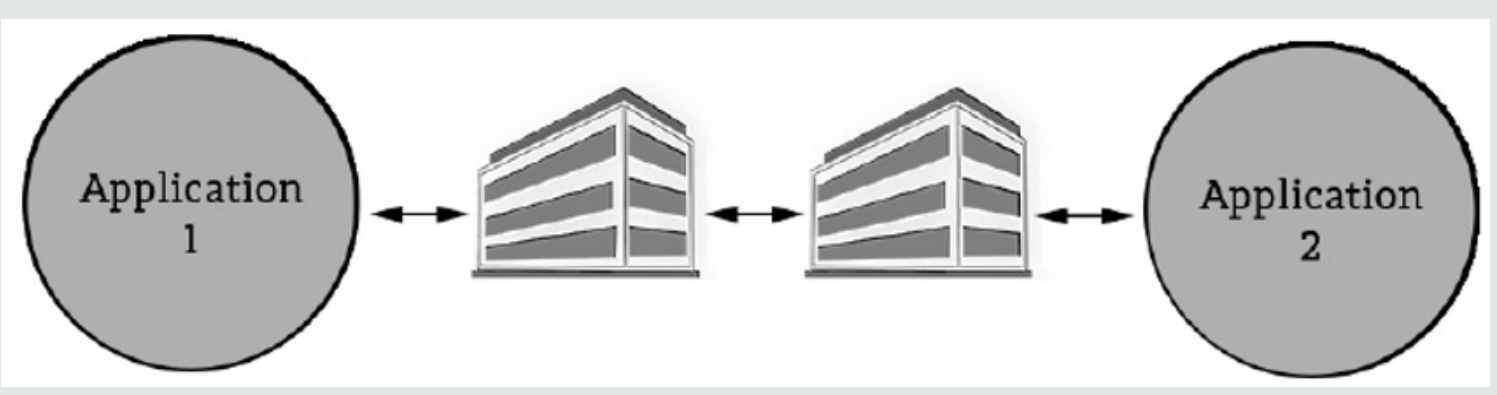

Figure 3: An example of interoperability using a bidirectional interface.

IFC proves very effective as a reference file during project coordination. In such a case, the sequence of design work of the team is as follows:

a. Designers use specialist applications and save results of their work on a current basis in native files,

b. They export results of their work to an IFC file from time to time,

c. Models saved in IFC files are used for the development of a single shared reference file of the interindustry model,

d. After performing arrangements based on the reference model, designers introduce necessary changes in their files and save them in native files, continuing design works,

e. The cycle is repeated.

Unfortunately, at the moment, the idea of interoperability by means of an IFC file is not perfect. Firstly, not all elements of native files are moved to the IFC model, and secondly the introduction of changes does not occur online. However, several leading producers of BIM software recently signed agreements concerning exchange of technical information covering among others the structure and content of native files, for the purpose of provision of more effective interfaces for data exchange. Current research confirms that the evolution of the IFC model is headed in the right direction, and the format itself is still being improved.

The basic elements used in BIM models are components. Because components are optimized in terms of repetitions, it is worth investing time in creating a component rather than use CAD models (2D or 3D). If a CAD model is copied, a completely new element if created, in addition to added information from the first occurrence. The use of very detailed and nested components should be absolutely minimized. Where possible, openings in the geometry of components should be avoided. It is also worth avoiding sequences and groups that add considerable weight to the model. Parametric components add more weight to the model than static components. It should be therefore considered whether a given component actually needs parametric flexibility. Unused components should be removed from the design on a current basis.

The term of 'efficient' or 'lean' modeling is frequently encountered in the literature. It also concerns BIM models. It is worth minimizing details of geometry so that they are visible only in a selected view or in a selected scale. Where possible, typical rules of 2D drawing adopted in the team can be followed in order to apply the proper level of complexity of the model. During creating views of a detail it is worth modeling hatches with filled areas, and not lines [14]. In the case of parts and sets of parts, it is worth limiting their development due to their considerable weight for the model. If they are necessary, it is worth considering creating parts in separate models, and connecting them with the original model.

In the case of attached files, unused bonds of all types should be removed. If a bond is located in a grid, then importing instead of connecting can increase the efficiency of the model. Raster images considerably reduce the efficiency of the model. Due to this, it is worth deleting sample renderings on a current basis, and unplugging unused map backgrounds. Monochromatic images are always smaller than colour images [15].

In the case of preparing variants of a design, it is better to use separate models for different variants of entire wings of the building (Figure 4). Design variants can be kept only under the condition that they are useful in the project. Even if the variants are not visible and active, after the introduction of changes in the main model, all variants are updated. It is worth considering whether the variants should be saved for a longer time in separate models that can be appropriately connected. 


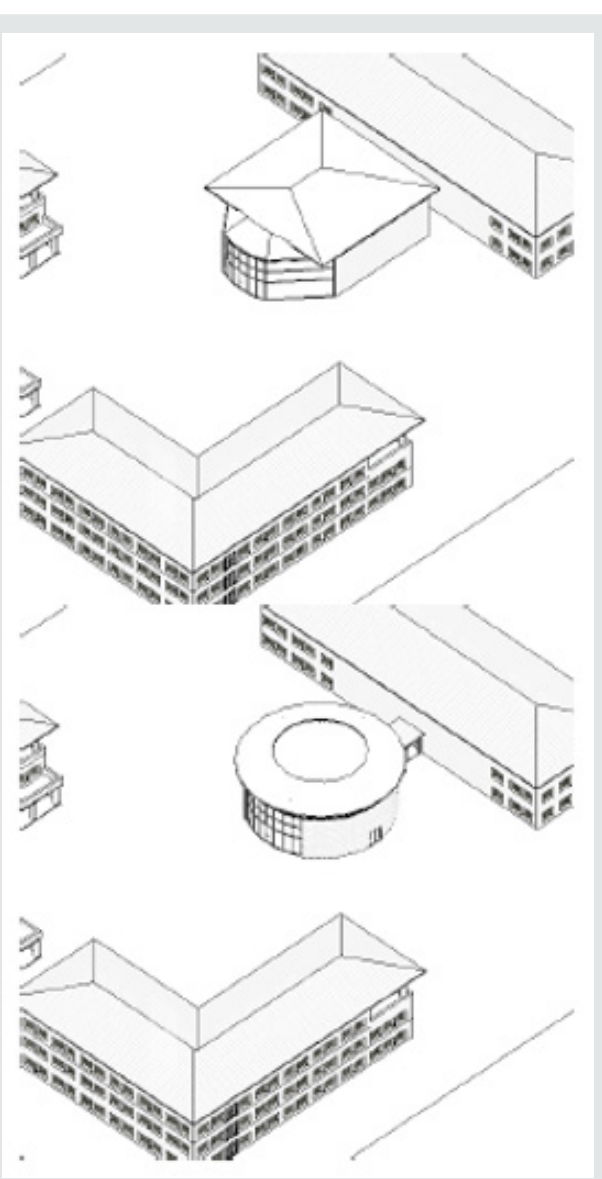

Figure 4: An example of two variants of an auditorium building.

The application of the aforementioned models of conduct in the scope of large complex buildings may not provide for optimum efficiency of model manipulation. In such cases, it is worth dividing the model into several separate dependent files. There are two basic ways to divide a model into project files:

i. By industry (e.g. HVAC, electric, etc.),

ii. By area (building, premises, parking lot, etc.).

\section{Conclusion}

An average design of a small object with full technical documentation for printing will easily reach a size of several hundred MB. If the work is done in a multidisciplinary way with a high level of detail, the BIM model can reach a size of even several GB (case of Freedom Tower - 2 GB). The efficiency of the BIM model depends on the knowledge, skills, and experience of the designer, as well as on the hardware environment for collaboration with the selected software. The application of the aforementioned good practices and the presented procedures in the scope of work optimization ensures a stable and effective design process. The presented guidelines were developed as a set of tools that can be used individually or in combination for the purpose of development of coherent BIM models possible to calculate and corresponding with the design concept.

\section{Acknowledgement}

The authors would like to thank the Dean of the Faculty of Geodesy and Cartography for funding the research and publication of this article.

\section{Disclosure Statement}

No potential conflict of interest was reported by the author.

\section{Funding}

This work was supported by the Faculty of Geodesy and Cartography, Warsaw University of Technology.

\section{References}

1. Shrivastava S, Chini A (2012) Using Building Information Modeling to Assess the Initial Embodied Energy of a Building. International Journal of Construction Management 12(1): 51-63.

2. Building SMART.

3. Seo MB, Ju KB (2013) A Study on the Interoperability between 2D Drawings and BIM-Based 3D Drawings. Open Journal of Social Sciences 1(5): $10-14$

4. Shafiq MT, Matthews J, Lockley SR (2013) A study of BIM collaboration requirements and available features in existing model collaboration systems. Journal of Information Technology in Construction 18: 148161.

5. Azhar S, Khalfan M, Maqsood T (2012) Building information modelling (BIM): now and beyond. Australasian Journal of Construction Economics and Building 12(4): 15-28.

6. AEC (UK) BIM Technology Protocol Version 2.1.1. Practical implementation of BIM for the UK Architectural, Engineering and Construction (AEC) industry.

7. Tomana A (2016) BIM - Innowacyjna technologia w budownictwie. [BIM - Innovative technology in construction]. Builder, Kraków.

8. Cohen R, Austin B, Bannister P, Bordass B, Bunn R (2017) How the commitment to disclose in-use performance can transform energy outcomes for new buildings. Building Services Engineering Research and Technology 38(6): 711-727.

9. Kasznia D, Magiera J, Wierzowiecki P (2017) BIM w praktyce. Standardy, wdrożenia, case study. [BIM in practice. Standards, implementations, case study.] Twarda binding, publishing house: Wydawnictwo Naukowe PWN.

10. Papadonikolaki E, Wamelink H (2017) Inter- and intra-organizational conditions for supply chain integration with BIM. Building Research \& Information 45(6): 649-664.

11. Isaac S, Curreli M, Stoliar Y (2017) Work packaging with BIM. Automation in Construction 83: 121-133.

12. Lorch R (2012) BIM and the public interest. Building Research \& Information 40(6): 643-644.

13. Arayici Y, Fernando T, Munoz V, Bassanino M (2018) Interoperability specification development for integrated BIM use in performance based design. Automation in Construction 85: 167-181.

14. Borkowski AS (2018) 0 przygotowaniu detali rysunkowych za pomocą modelu BIM i niezależnie od niego. [About preparing drawing details using the BIM model and independently of it.] Inżynieria i Budownictwo 74(1): 33-34.

15. Muller MF, Garbers A, Esmanioto F, Huber N, Loures ER, et al. (2017) Data interoperability assessment though IFC for BIM in structural design - a five-year gap analysis. Journal of Civil Engineering and Management 23(7): 943-954. 
(c) $(\mathrm{P}$

This work is licensed under Creative

Commons Attribution 4.0 License

To Submit Your Article Click Here: Submit Article

DOI: $10.32474 /$ TCEIA.2019.03.000164

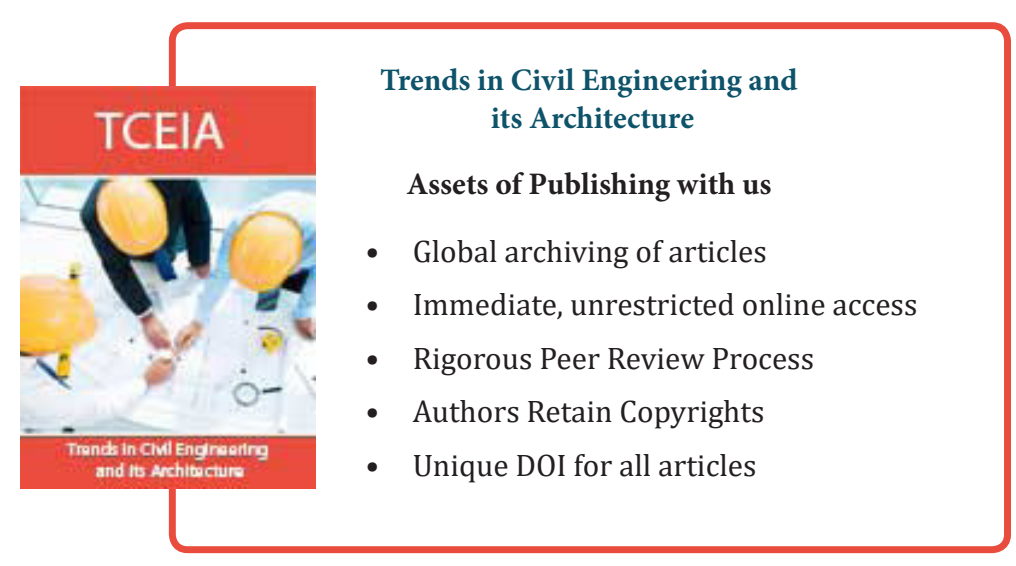

